\title{
Composite Web Services: A Game Theory Application for Assessing the Workload Sharing using Shapley Value
}

\author{
Ch. Ram Mohan \\ Reddy \\ Research scholar \\ M S Ramaiah \\ Institute of \\ Technology, \\ Bangalore - 54 India
}

\author{
K. Sailaja Kumar \\ M S Ramaiah \\ Institute of \\ Technology, \\ Bangalore - 54 India
}

\author{
D. Evangelin \\ Geetha \\ M S Ramaiah \\ Institute of \\ Technology, \\ Bangalore - 54 India
}

\author{
T. V. Suresh \\ Kumar \\ M S Ramaiah \\ Institute of \\ Technology, \\ Bangalore - 54 India
}

\begin{abstract}
In distributed environment the changes and challenges faced by composite web services in their network environment are enormous. The primary issue in these systems is to distribute the load among various components of the composite web services to improve the performance through minimizing the response time. In this paper, we present a methodology to estimate the load sharing among composite web services using traditional workflow concept combined with game theory approach. In addition, we have developed a simulation model and observed that the results are promising for a better understanding of workload sharing among individual web services. We obtained the stable solution for ensuring the cooperation of the web services which further helps in capacity planning in composite web services network environment.
\end{abstract}

\section{Keywords}

Composite Web services, Shapley value, Workload, Flow Games.

\section{INTRODUCTION}

The workload is a key issue in any Web services environment. Workloads change; they may grow or shrink, depending on prospective business and technology evolution. The growth of the workload initiates due to; newly built applications tend to increase the density of the transactions, its way of processing request and also the environment in which it can be enhanced. The unpredictable demand, which is a portion of the workload that shows up at random times and takes up all of the system capacity [5].

A Procedural process needs to be methodical in its ability to balance load and its service time. Those compositions that are static, each service in a process are bound to its design time. A designer who is responsible for solving the problem resolves the issue by searching for a particular service, and the analysis is done depending on the metrics; load capacity, expense, dependability, service time [1] [3] [4]. In order to analyze the entire QoS of a process and estimate its performance, many Mathematical methods are used [1]. Second replacement for estimating process QoS would be the utilization of simulation analysis [14]. Simulation plays a prominent role in assessing the QoS of a procedural process even before its undeniable execution. Those compositions that are dynamic in nature, the true coherence of the process cannot be predicted until it is triggered. Having both the composition's performance information helps in giving feedback on the productivity of the composition of a process.

Composite services are a typical aggregation of the complex process. In the context of web services, we consider composite web services as a single unit. The performance of the composite web services encompasses the effective resource usage and sharing of the workload in service oriented environment. It is difficult, knowing the workload of the composite web services in service oriented applications. The flow game approach is adopted to determine a characteristic function for workload sharing with respect to various aspect's software specifications. Workload fluctuations in the composite web services may result in the congestions; delay, etc. in the resource utilization. Suitable workload sharing can be determined by considering the maximum flow value for sharing of workload. Fundamentally, a composite web service is a collation game, and one of the applications of the shapely value is to measure the relative importance of individual service contribution. A concept called Shapley Value, a product of the collaborative game theory is proposed in [17]. Shapley Value provides scope for a decision on the utilization of players during a game which is said to be collaborative or possibly cooperative. Making a rudimentary assumption that the benefits obtained from the web services are low when compared to the benefit which is obtained when incorporating new services, the Shapley Value determines the contribution of each web service to the collation and hence estimates the workload of various web services accurately.

In this paper, we apply the usefulness of Shapley value in the context of composite web services workload estimation in Travel reservation application. We proposed a methodology based on flow game to solve the problem of workload sharing. The flow of the requests between the web services is modeled using flow diagram. This approach helps to obtain a stable solution for the cooperation of web services.

The rest of the paper is organized as follows. In section 2, we discuss the related literature and their limitations. In section 3, we propose the basic concepts of Shapley value and flow game. Section 4 describes the proposed methodology to estimate the contribution of web services in sharing the workload using flow game and the Shapley value. The illustration of the methodology is given with the help of a case study on "Travel Reservation", Simulation and Results are discussed in Section 5 and in Section 6. The paper ends with a conclusion and future work. 


\section{RELATED WORK}

In this section, we review the related literature in the area of Workload sharing in Service oriented web services known as composite web services and research gaps identified.

The combination of many services or single service are executed by one site, or different sites are performed by composite service and also performance depends on underlying infrastructure, composed of applications and composite web service. The problems which are commonly related to insufficient bandwidth during peak times servers which are overloaded, uneven server loads, delivery of dynamic content, shortage of connections between servers of applications and database service, failure of third party services and delivery of multimedia contents. It is also important to understand the behavior of web service provider which is used to identify the problems that impair the composite web service performance.

Performance analysis of the composite web service is a significant issue in providing and choosing a service for service providers who are interested in getting a better quality of Systems. Workflow is an important tool used for performance analysis [9] [10] [12] [18] [21] [23] [25].

A service is needed to reduce the huge state space in the analysis, an experimental method to be conducted using performance analysis of the composite web service. Composite web service is a combination of multiple web services to accomplish a complex task. Different workflow patterns are shown in [6]. It presents scheduling of web services requests achieving better performance. Different experiments showed in applying to composite web services are scheduled and synchronize workflow patterns. Different workflow patterns that can implement composite web services are still an open issue.

By offering limited capabilities by the elementary web service, the composite web service composes this elementary web service to perform the complex request. The coordination between elementary services and the activities of composite services are defined by the control flow graph, and data graphs are controlled by composite service. The response time of a request which is given by request load and the architectural environment is important by the service provider. When servers are heterogeneous, and a number of elementary web services are unpredictable in nature and propose the analytical formula for composite web service of mean response time will guarantee the quality of service.

The HP laboratory which is proposed by eflow is a platform for performing the specification, enactment and administering the composite services, where the composite web services are described with graphics, which are composed of service nodes, decision nodes, and event nodes. The good essentials of understanding the dynamic characteristics and adaptability of composite web services that are provided by eflow is considered the holistic aspect by performing and selecting the services. These services are selected assuming execution time and cost by neglecting QoS metrics. Eflow and Web flows are workflow management systems that offer support in the selection of services, which are only for individual tasks and also selected according to quality constraints.

The workflow of a streamlined end to end functionality for human users or other systems is composed by the web service. The problem faced during scheduling the web service requests to providers is relevant to business domains. They are depended on the multi-tired service by providing heuristics for scheduling the service request from the many business processes. This business values metric is maximized in a scalable manner across the overall workflow.

To assist travelers during many stages of traveling by making the process easier are developed by web-based web applications/web services. The e-commerce applications or information portals are comprised of web-based applications by explaining the preliminary study for travel based website by composite web service. The main aim of the model is to assist travelers a generic design for getting travel information through the website and searching the appropriate information through internet process. By merging various web services and modeling into one service can be embedded in travel based website.

An algorithm to assess the workload of the individual server for transaction processing system in distributed database at early stages of system development is proposed in [20]. Developed a model using UML2.0 and illustrated with a case study.

Shapley value algorithm and its application among supply chain coalition by analyzing some good qualities and shortcomings in the Shapley value method are presented in [24]. To avoid diffusion of information in a social network [15] present locating a small subset of significant players in a given social network, to perform a certain task of information distribution. Dynamic flow problems are said to be originated in many applications. These Dynamic flow problems include; production-distribution systems, communication systems and scheduling the logistic transportation. An approach to research on the dynamic flow problem can be simulated in two ways; one is networks with discrete time variants, secondly network with continuous time. Thus, Shapley value which is a concept from the cooperative game theory remains an approach for solving the transshipment problem in order to maintain stability in the network that it is presented in [16]. In summary, we identified the research gaps in applying shapely value to web services/ Composite web services.

\section{BASIC CONCEPTS}

\subsection{Shapley Value}

The Shapley value was introduced by Shapley [17] as a method for each player to assess a priori the benefits he would expect from playing a game. Shapley value is an important tool in cooperative game theory, to estimate the level of contribution of each player in the game.

\subsection{Flow Games}

In distributed network environment sending requests from one resource to another is considered as the mechanism of flow. These requests are termed as requests flows units. In the web services environment, flow units are requests, web pages, processed data, etc. Consider the distributed network as a directed graph $\mathrm{G}(\mathrm{V}, \mathrm{E})$ where $\mathrm{V}$ is the vertex/node set and $\mathrm{E}$ is the edge set. In composite web services, a flow of requests in the network is specified using the directed graph. The vertices of this directed graph represent the hardware resources available to the users, service providers, and web servers. The directed edges with the weights on them show the amount of data that flow from the starting resource to ending resource of the composite web services. The user requests will enter into the network through the source nodes and are then routed to sink nodes. This process termed as flow games. A flow game is a simple way of sending requests from one place to another, with the cooperation of resources [16]. 
Consider the flow game as a directed graph $\mathrm{G}(\mathrm{V}, \mathrm{E})$ given in [13]. An edge from node $i$ to node $j$ is denoted as $\mathrm{e}_{i j}$. The edge $\mathrm{e}_{i j}$ has a request processing capacity $\mathrm{cp}_{i j}$. The flow of such requests is considered as a vector $\mathrm{M}=\left(\mathrm{m}_{i j}\right)$ in which the component $\mathrm{m}_{i j}$ represents the number of request flowing from node $\mathrm{i}$ to node $\mathrm{j}$. In the flow game, the player set $\mathrm{N}$ is a finite and non-empty set which owns the edges in the graph. The cooperation flow game is defined as the characteristic function (V) which represents the maximum number of requests that a coalition can sustain using its own portion of the network. For a game $(\mathrm{N}, \mathrm{v})$, the $\mathrm{v}$ is defined as the set of all vectors $M$ satisfying $\sum \mathrm{m}_{\mathrm{iv}}(\mathrm{V})$ for all $\mathrm{V} \subset \mathrm{N}$ and $\sum \mathrm{m}_{\mathrm{i}}=$ $\mathrm{v}(\mathrm{N})$. The conditions expressed on the $(\mathrm{N}, \mathrm{v})$ ensure that an allocation of $\mathrm{v}(\mathrm{N})$ will be stable during the cooperation between the resources $\mathrm{N}$ [16].

\section{METHODOLOGY}

The composite web services need to be efficient in terms of its service time and contribution in handling heavy workloads. Hence, it is required to measure the contribution of the servers in the composite environment so as to improve the efficiency based on the measures. In this paper, a methodology is proposed to estimate the contribution of the servers that are processing the requests in cooperation. The well-known Shapley value concept from cooperative game theory has been exploited in the estimation along with the flow games. The procedure involved in the methodology is explained as follows:

i. Consider the web services that are to be participated in the composite web services

ii. Consider the architecture of the composite web services if it already exists, otherwise, design the architecture of the composite web services

iii. Develop the flow graph representation of the architecture network

iv. Solve the flow graph using cooperative game theoretic approach

v. Calculate the contribution of the individual web service using Shapley value. i. Consider the web services that are to be participated in the composite web services

Web services are "self-contained, self-describing modular applications that can be published, located, and invoked across the Web". The web services, which can be combined to provide services in a cooperative way are to be identified.

ii. Consider the architecture of the composite web services if it already exists, otherwise, design the architecture of the composite web services

The Web services architecture models software as individual components available on the Web. In general, composite web services are a 3-tier architecture. It includes the web client, web server and the web services registered in the composite web service. Hence, the components of the web service, for instance, a composition of mail service and the communication between the web services are to be presented in the architecture. Sample web services architecture is shown in Figure 1.

iii. Develop the flow graph representation of the architecture network

The flow graph developed for the sample composite web services architecture is given in Figure 2. The nodes of the graph represent the resources in the composite web services environment, and the arcs show the communication between them. Let WC be the web client, WSR be the web server and $\mathrm{WS}_{1}, \mathrm{WS}_{2}, \ldots, \mathrm{WS}_{\mathrm{n}}$ be the web services that are participating in the composite web services. The weights shown in the arcs of the graph represent the ability to process the request/data of the hardware resource at the 'from' end of the arc. Hence, let $\mathrm{w}$ be the processing capacity of the $\mathrm{WC}, \mathrm{ws}_{1}, \mathrm{ws}_{2}, \ldots, \mathrm{w}_{\mathrm{n}}$ be the capacity of the web server that can be processed and sent for the web services $\mathrm{WS}_{1}, \mathrm{WS}_{2}, \ldots, \mathrm{WS}_{\mathrm{n}}$ respectively. Let $\mathrm{wr}_{1}, \mathrm{wr}_{2}, \ldots, \mathrm{wr}_{\mathrm{n}}$ be the capacity of the web services $\mathrm{WS}_{1}, \mathrm{WS}_{2}, \ldots, \mathrm{WS}_{\mathrm{n}}$ respectively. 


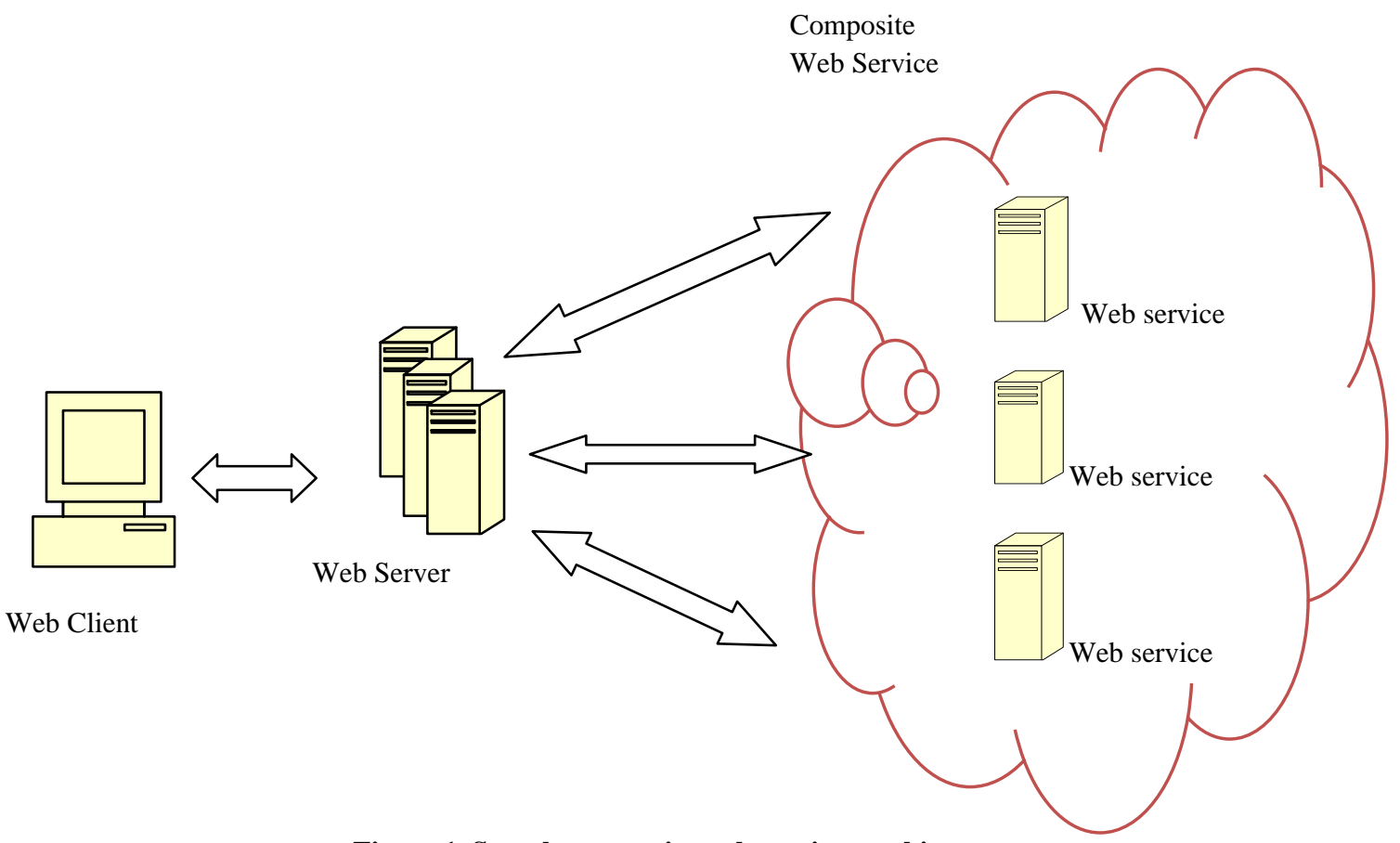

Figure 1 Sample composite web services architecture

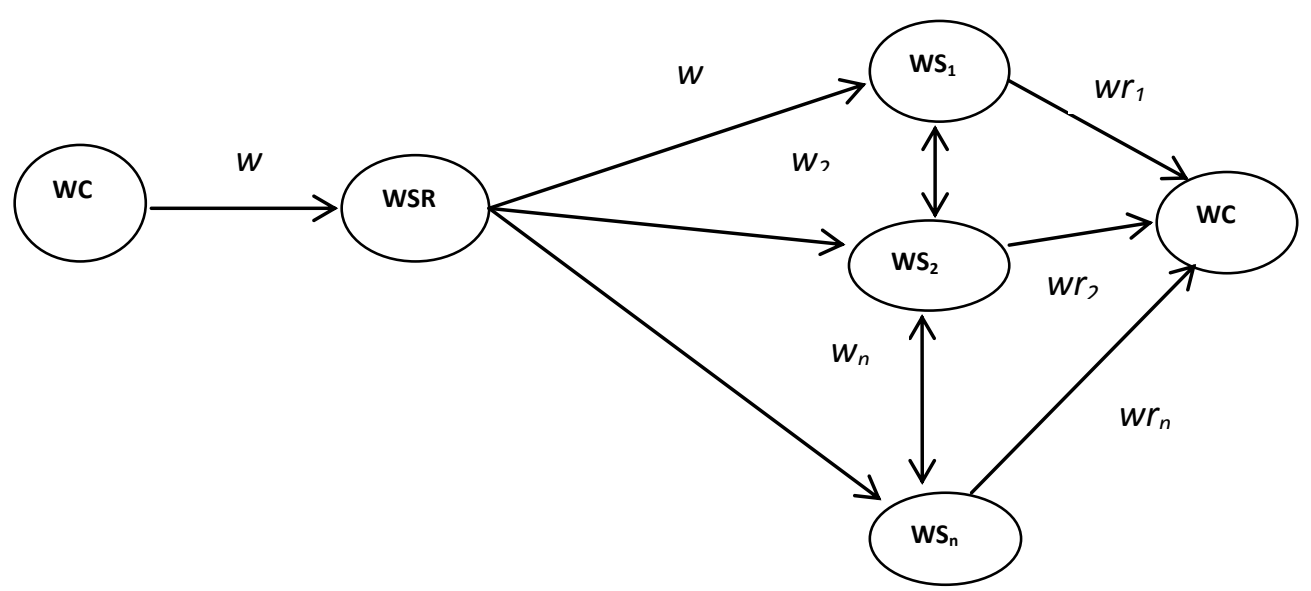

Figure 2 Flow graph for the composite web services

iv. Solve the flow graph using cooperative game theoretic approach

The composition of Web services helps as a paradigm for enabling Business-to-Business (B2B) collaborations. The web services that are participating in the collaboration have to work in a cooperative way to provide the services as per the need of the clients. The flow game of the game theoretic approach helps to solve the coalition between the composite web services. Let $\mathrm{n}$ web services participating in the coalition be the players in the player set $\mathrm{N}$. The edges in the graph are owned by the players and a coalition owns the edges of its members. An n-resource cooperation flow game is defined as a characteristic function of the game represents the maximum flow value for coalition through the network of its members. v. Calculate the contribution of the individual web service using Shapley value

The Shapely value helps to measure the relative importance of individual service contribution. In other words, the Shapley value can be seen as a measure of the utility of players in a collaborative or cooperative game. In the proposed methodology, it is required to calculate the contribution of individual web services, Shapley value concept is used to measure the individual contribution in the coalition. The contribution of individual service is computed using Shapley Value as per the following formula 4.1 [16]

$$
(N, v)=S V_{i}=\sum_{\{s \in S \subseteq N\}} \frac{(|S|-1) !(|\mathrm{n}|-|S|) !}{|n| !}[\mathrm{v}(S)-\mathrm{v}(S-\{\mathrm{i}\})]
$$

For all $\mathrm{i} \in \mathrm{N}$ and $\mathrm{v}$ are the web services 


\section{METHODOLOGY OF SHAPLEY VALUE APPLIED TO 'TRAVEL RESERVATION' COMPOSITE WEB SERVICES}

For illustration purpose, the case study on Travel Reservation Scenario is considered. The case study is described as follows: The travelers prefer reservation for their travel location through a travel agent. The main objective of the travelers is to get the best combination of services like airline/bus service, car service, accommodation service, etc. The travel agent's aim is to satisfy the traveler's needs and earn money. In this scenario, the traveler submits the requests to the Travel agent and the responsibility of the Travel Agent is to find the best combinations of services that satisfy the customer's requirements. This scenario provides a fulfilled response to the traveler as well as the travel agent if the required services work in coalition. Hence, the proposed approach is applied to this case study to identify the contribution of each web service participating in the composite web services.

i. Consider the web services that to be participated in the composite web services

Any traveler who wishes to use an Airline service may search for Car rental service and Hotel service. Hence, these three services are considered to participate in a coalition.

ii. Design the architecture of the composite web services
The architecture of the composite web services with the identified web services for Travel Agent is given in Figure 3. The clients (users/travelers) submit the requests to the Travel Agent. The requests are processed and forwarded to the composite web services. The composite web services, Airlines, Car Rental and Hotel, process the requests in coalition and provide the services to the users.

iii. Develop the flow graph representation of the architecture network

The flow graph developed from the architecture is given in Figure 4. The composite web services network flow diagram consist of Travel Agent (TA), Traveler (T) and composite web services, Airline (A) service, Car (C) service, Hotel (H) service as presented in Figure 5. In this network, requests will be processed by the web services in collaboration.

The weights presented on the edges are the capacities of the edges i.e. the number of requests generated by the TA and the number of requests that can be processed by the web services respectively. The three web services own the edges S1, S2, and S3 respectively. Precisely, S1 (the upper edge) owns the resources (TA, C) and $(\mathrm{C}, \mathrm{T})$ with the capacities 24 and 27. S2 (the middle edge) owns the resources (TA, A), (A, C), (A, H) and (A, T) with the capacities 56 and 49. S3 (the bottom edge) owns the resources $(\mathrm{TA}, \mathrm{H})$ and $(\mathrm{H}, \mathrm{T})$ with the capacities 20 and 24.

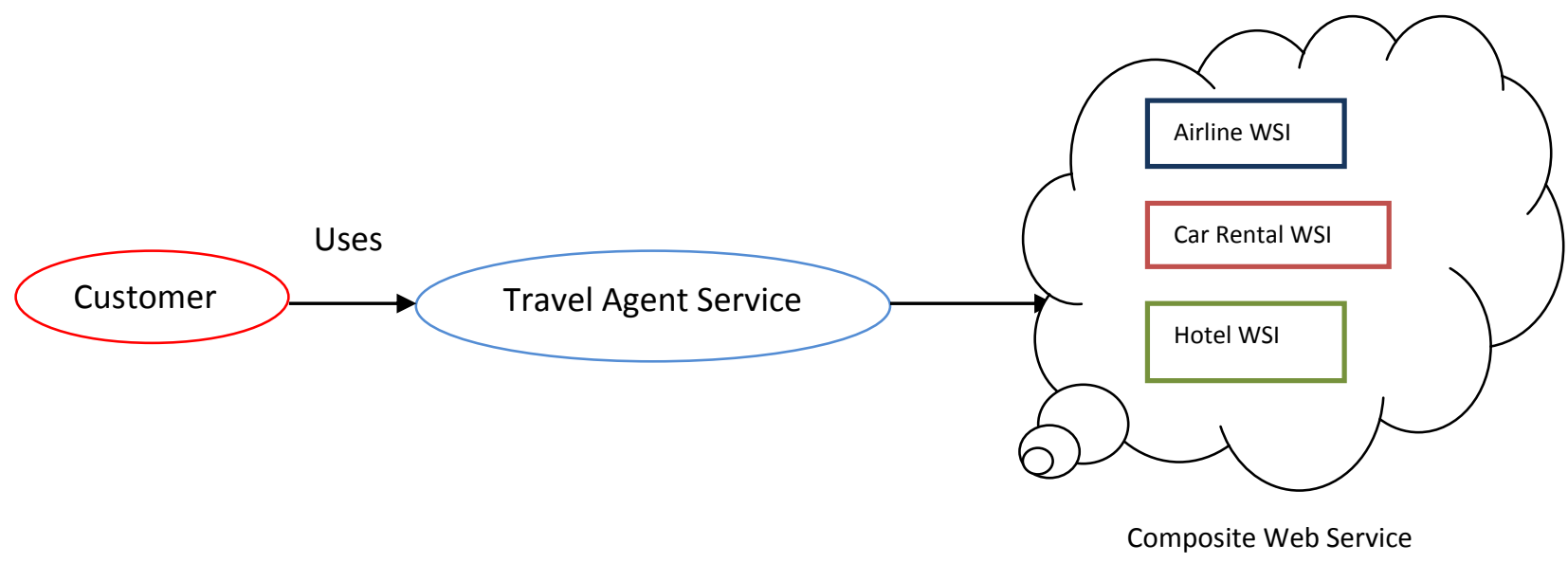

Figure 3. Architecture of Travel Agent composite web service

iv. Solve the flow graph using cooperative game theoretic approach

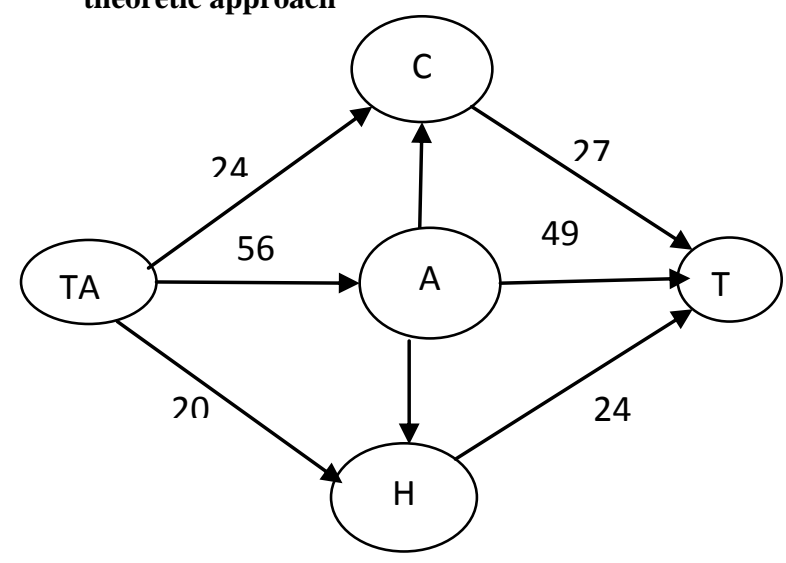

Figure 4. Composite web services flow diagram
A cooperation flow game is constituted with the three players representing composite web services $\mathrm{C}, \mathrm{A}, \mathrm{H}$. In the flow diagram, the arcs are owned by the players that are $\mathrm{S} 1, \mathrm{~S} 2$, and S3. The edges represent the coalition among the composite web services. The characteristic functions representing the maximum flow value for coalitions among these composite web services are given below.

$$
\begin{gathered}
\mathrm{v}(\{\mathrm{C}\})=\operatorname{Min}(24,27)=24 \\
\mathrm{v}(\{\mathrm{A}\})=\operatorname{Min}(56,49)=49 \\
\mathrm{v}(\{\mathrm{H}\})=\operatorname{Min}(20,24)=20 \\
\mathrm{v}(\{\mathrm{A}, \mathrm{C}\})=\operatorname{Min}(24+56,27+49)=76 \\
\mathrm{v}(\{\mathrm{A}, \mathrm{H}\})=\operatorname{Min}(56+20,49+24)=73 \\
\mathrm{v}(\{\mathrm{C}, \mathrm{H}\})=\operatorname{Min}(24+20,27+24)=44 \\
\mathrm{v}(\{\mathrm{A}, \mathrm{C}, \mathrm{H}\})=\operatorname{Min}(24+56+20,27+49+24)=100
\end{gathered}
$$


v. Calculate the contribution of the individual web service using Shapley value

Shapley value for the individual web service A, C and $\mathrm{H}$ is calculated as follows:

$\mathrm{SVC}=[\mathrm{v}(\{\mathrm{C}\})-\mathrm{v}(0)] 1 / 3+[\mathrm{v}(\{\mathrm{A}, \mathrm{C}\})-\mathrm{v}(\{\mathrm{A}\})] 1 / 6+$ $[\mathrm{v}(\{\mathrm{C}, \mathrm{H}\})-[\mathrm{v}(\{\mathrm{H}\})] 1 / 6+[\mathrm{v}(\{\mathrm{A}, \mathrm{C}, \mathrm{H}\})-\mathrm{v}(\{\mathrm{A}, \mathrm{H}\})] 1 / 3$ $=(24-0) 1 / 3+(76-49) 1 / 6+(44-20) 1 / 6+(100-73) 1 / 3$ $=25.5$

$$
\begin{aligned}
\text { SVA }= & {[\mathrm{v}(\{\mathrm{A}\})-\mathrm{v}(0)] 0 ! 2 ! / 3 !+[\mathrm{v}(\{\mathrm{A}, \mathrm{C}\})-\mathrm{v}(\{\mathrm{C}\})] } \\
1 ! 1 ! / 3 !+ & {[\mathrm{v}(\{\mathrm{A}, \mathrm{H}\})-\mathrm{v}(\{\mathrm{H}\})] 1 ! 1 ! / 3 !+} \\
& {[\mathrm{v}(\{\mathrm{A}, \mathrm{C}, \mathrm{H}\})-\mathrm{v}(\{\mathrm{C}, \mathrm{H}\})] 2 ! 0 ! / 3 ! } \\
= & (49-0) 1 / 3+(76-24) 1 / 6+(73-20) 1 / 6+(100-44) 1 / 3 \\
= & 52.5
\end{aligned}
$$

$\mathrm{SVH}=[\mathrm{v}(\{\mathrm{H}\})-\mathrm{v}(0)] 1 / 3+[\mathrm{v}(\{\mathrm{A}, \mathrm{H}\})-\mathrm{v}(\{\mathrm{A}\})] 1 / 6+$ $[\mathrm{v}(\{\mathrm{C}, \mathrm{H}\})-[\mathrm{v}(\{\mathrm{C}\})] 1 / 6+[\mathrm{v}(\{\mathrm{A}, \mathrm{C}, \mathrm{H}\})-\mathrm{v}(\{\mathrm{A}, \mathrm{C}\})] 1 / 3$ $=(20-0) 1 / 3+(73-49) 1 / 6+(44-24) 1 / 6+(100-76) 1 / 3$ $=22$

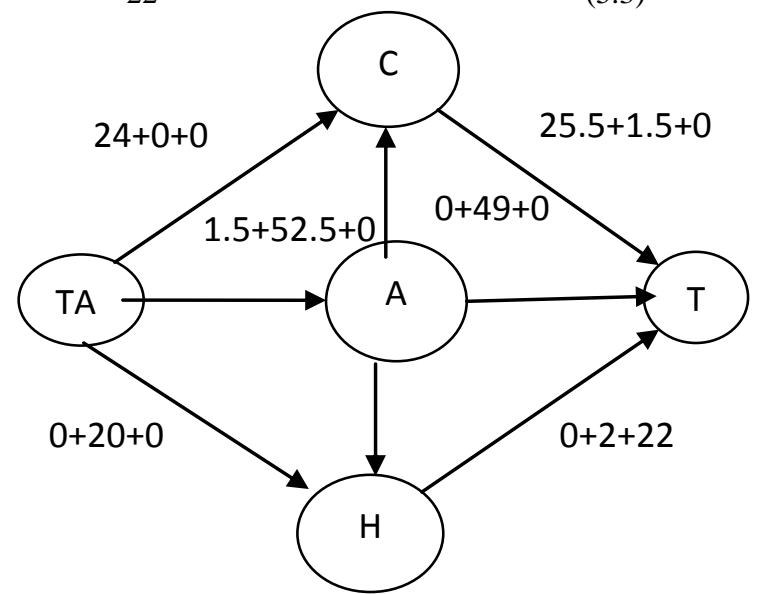

Figure 5. Flow diagram using shapely value w.r.t web services

From the above results we observed that

$\mathrm{SVA}=25.5>24=\mathrm{v}(\mathrm{C})$

$\mathrm{SVC}=52.5>49=\mathrm{v}(\mathrm{A})$

$\mathrm{SVH}=22>20=\mathrm{v}(\mathrm{H})$

$\mathrm{SVA}+\mathrm{SVC}=78>76=\mathrm{v}(\mathrm{C}, \mathrm{A})$

$\mathrm{SVA}+\mathrm{SVH}=47.5>44=\mathrm{v}(\mathrm{C}, \mathrm{H})$

$\mathrm{SVC}+\mathrm{SVH}=74.5>73=\mathrm{v}(\mathrm{A}, \mathrm{H})$

The Shapely value for the cooperative game is obtained as SV $=(25.5,52.5$, and 22). This may be based on the demand for these services involved in the application.
Also SVA+ SVC $+\mathrm{SVH}=25.5+52.5+22=100=\mathrm{v}(\mathrm{C}, \mathrm{A}, \mathrm{H})$

From equation (5.4), it is observed that the Airline service contributes $52.5 \%$ Car service contributes $25.5 \%$, and Hotel service contributes $22 \%$ in the coalition of CWS used in Travel Reservation Application. It is also observed that the Airline service plays a major role in the coalition, whereas Hotel service contributes a lesser contribution. It is also observed that we have a stable solution for the cooperation of the three web services. Hence, we conclude that the application of Shapley value in web services, in the context of workload sharing for load balancing using workflow games, gives a stable solution.

\section{SIMULATION RESULTS AND DISCUSSION}

The terms simplicity, flexibility, interoperability and reuse of services are chosen in composite web services. In modular applications the services are published, advertised, discovered and invoked across various networks. It can be Internet and Intranet. Prior implementation, if the recent trends are available, will be useful. In composite web services, the study compares the workload and response time parameters of various web services which will help the developer in early development life cycle. This chapter presents load sharing among composite web services in the simulated and deployment environments. Before actually placing on the web, web services can be simulated and tested from the actual deployment environments which show similar results.

We have simulated the environment of CWS with Airline (A), Car (C) and Hotel $(\mathrm{H})$ services for travel reservation application. The simulation model is implemented in Java 1.7 with hardware configuration Intel(R) Core(TM) 2Quad CPU Q6600@2.40GHz. 2 GB RAM. We established the workload sharing among elements of CWS, i.e., A, C and $\mathrm{H}$ through simulation. The results are obtained for various requests arriving at TA and tabulated in Table 1. For simplicity, we considered maximum 95 requests arriving at TA. In majority cases, the contribution of $\mathrm{A}$ is more in processing total requests arriving at TA when compared to $\mathrm{C}$ and $\mathrm{H}$ services. It is also observed that the combined contribution of $\mathrm{C}$ and $\mathrm{H}$ is almost equal to A's contribution; this may be because several customers may not be interested in $\mathrm{C}, \mathrm{H}$ services as they are optional. Also, the deviation is similar in all these cases. This proves that Shapely value is effective in the case of CWS to improve performance through sharing the workload. The services $\mathrm{A}, \mathrm{C}$ and $\mathrm{H}$, which we have considered as three players in the game, contributed in a linear way in the coalition.

Table 1 Simulation results of CWS

\begin{tabular}{|c|c|c|c|c|c|c|}
\hline & \multicolumn{3}{|c|}{ Contribution of } & \multicolumn{3}{c|}{$\begin{array}{c}\text { Percentage of } \\
\text { Composite Web Services }\end{array}$} \\
\hline $\begin{array}{c}\text { No. } \\
\text { of Request } \\
\text { arriving at TA }\end{array}$ & $\begin{array}{c}\text { Airline } \\
\text { service }\end{array}$ & $\begin{array}{c}\text { Car } \\
\text { Service }\end{array}$ & $\begin{array}{c}\text { Hotel } \\
\text { Service }\end{array}$ & $\begin{array}{c}\text { Airline } \\
\text { service }\end{array}$ & $\begin{array}{c}\text { Car } \\
\text { Service }\end{array}$ & $\begin{array}{c}\text { Hotel } \\
\text { Service }\end{array}$ \\
\hline 25 & 19.67 & 1.67 & 3.67 & 78.67 & 6.67 & 14.67 \\
\hline 30 & 21.33 & 3.33 & 5.33 & 71.11 & 11.11 & 17.78 \\
\hline 35 & 23 & 5 & 7 & 65.71 & 14.29 & 20 \\
\hline
\end{tabular}




\begin{tabular}{|c|c|c|c|c|c|c|}
\hline 40 & 24.67 & 6.67 & 8.67 & 61.67 & 16.67 & 21.67 \\
\hline 45 & 26.33 & 8.33 & 10.33 & 58.52 & 18.52 & 22.96 \\
\hline 50 & 28 & 10 & 12 & 56 & 20 & 24 \\
\hline 55 & 29.67 & 11.67 & 13.67 & 53.94 & 21.21 & 24.85 \\
\hline 60 & 31.33 & 13.33 & 15.33 & 52.22 & 22.22 & 25.56 \\
\hline 65 & 33 & 15 & 17 & 50.77 & 23.08 & 26.15 \\
\hline 70 & 34.67 & 16.67 & 18.67 & 49.52 & 23.81 & 26.67 \\
\hline 75 & 36.33 & 18.33 & 20.33 & 48.44 & 24.44 & 27.11 \\
\hline 80 & 38 & 20 & 22 & 47.5 & 25 & 27.5 \\
\hline 85 & 39.67 & 21.67 & 23.67 & 46.67 & 25.49 & 27.84 \\
\hline 90 & 41.33 & 23.33 & 25.33 & 45.93 & 25.93 & 28.15 \\
\hline 95 & 43 & 25 & 27 & 45.26 & 26.32 & 28.42 \\
\hline
\end{tabular}

Table 2 Statistical results for CWS

\begin{tabular}{|l|c|c|c|c|c|c|}
\hline \multirow{2}{*}{\multicolumn{1}{c|}{ Statistics }} & \multicolumn{3}{|c|}{$\begin{array}{c}\text { Contribution of } \\
\text { Composite Web Services }\end{array}$} & \multicolumn{3}{c|}{$\begin{array}{c}\text { Percentage of } \\
\text { Contribution of Composite of Web } \\
\text { Services }\end{array}$} \\
\cline { 2 - 7 } & $\begin{array}{c}\text { Airline } \\
\text { service }\end{array}$ & $\begin{array}{c}\text { Car } \\
\text { Service }\end{array}$ & $\begin{array}{c}\text { Hotel } \\
\text { Service }\end{array}$ & $\begin{array}{l}\text { Airline } \\
\text { service }\end{array}$ & $\begin{array}{l}\text { Car } \\
\text { Service }\end{array}$ & $\begin{array}{l}\text { Hotel } \\
\text { Service }\end{array}$ \\
\hline Max & 43 & 25 & 27 & 78.67 & 26.32 & 28.42 \\
\hline Mean & 31.33333 & 13.33333 & 15.33333 & 55.462 & 20.31733 & 24.222 \\
\hline $\begin{array}{l}\text { Correlation between } \\
\text { arrival pattern and service } \\
\text { pattern }\end{array}$ & 1 & 1 & 1 & 0.934308 & 0.934256 & 0.9342558 \\
\hline
\end{tabular}

From Table 2 it is observed that the contribution of service A in processing the requests arriving at $\mathrm{TA}$ is more compared to $\mathrm{C}$ and $\mathrm{H}$ services. The correlation between the no. of requests arriving and the no. of requests processed by individual web service and their contribution is identified. It is observed that the correlation coefficient is 1 and near to 1 for all the web services which indicate strong correlation. The strong value also suggests that due to the Shapley Value approach, the workload sharing is optimal, and the contribution of individual web service in the coalition is equal.

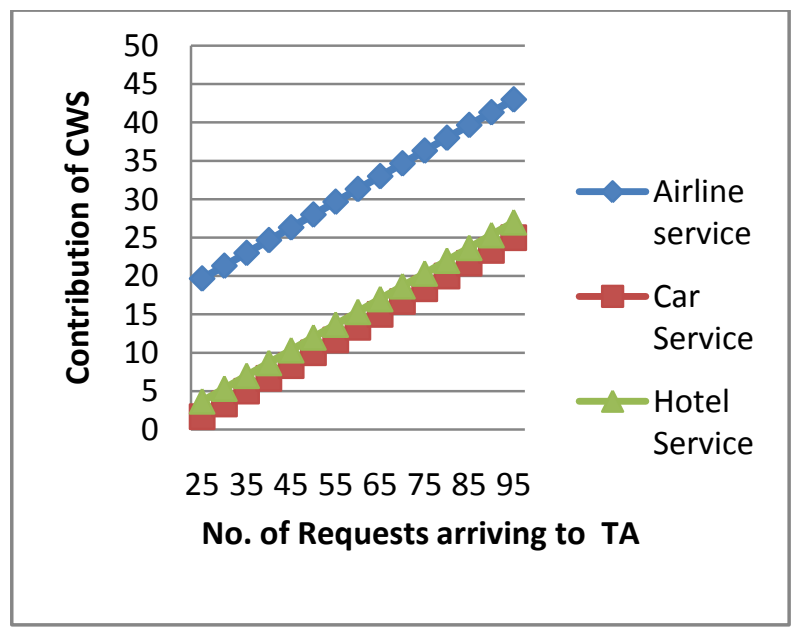

Figure 6 No. of requests arriving vs. No. of requests processed by individual web service

The graph is plotted by considering the no. of requests arriving vs. no. of requests processed by individual web service and is presented in Figure 6. It is observed that the services $\mathrm{A}, \mathrm{C}$ and $\mathrm{H}$ which we have considered as three players in the game have contributed in a linear way in the coalition.

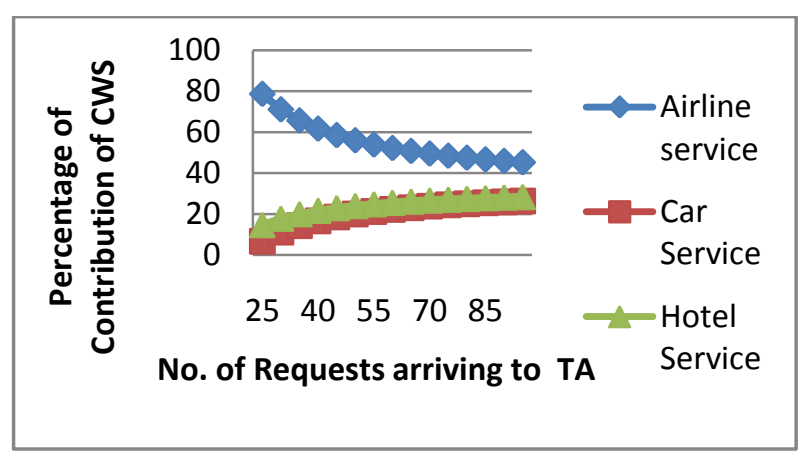

Figure 7 No. of requests arriving vs. contribution of individual web service in processing the requests

The graph is drawn by considering the no. of requests arriving vs. contribution of individual web service in processing the requests and is presented in Figure 7. It is interesting to note that the relative contribution of $\mathrm{A}$ is more, and that reflects the sharing of the workload with other services $\mathrm{C}$ and $\mathrm{H}$. This means that at the initial processing of requests arriving at TA, the users have not chosen $\mathrm{C}$ and $\mathrm{H}$ services. However when the no. of requests begin increasing for TA, there is stability among all three services, which validates the flow game approach.

\section{CONCLUSION}

Web services in the distributed environment face many changes and challenges in their network environment. Performance parameters, such as the capacity of resources, 
workload, etc., are driving forces in minimizing the response time. The primary issue regarding these systems is how to distribute the load among various components of composite web services. In this chapter, we estimated the load sharing among composite web services using traditional workflow concept combined with game theory approach which helps in capacity planning. We developed a methodology using 'flow game' theory and obtained simulation results. The results are promising for a better understanding of workload sharing among individual web services of a CWS. We obtained the stable solution for the cooperation of the web services. Further research could be carried out by extending the approach to the additional services in the flow network and applying layered network approach for the same can also be discussed.

\section{REFERENCES}

[1]. Cardoso J., Miller. J., Sheth, A., and Arnold. J., "Modeling Quality of Service for Workflows and Web Service Processes", in the VLDB Journal, 2002.

[2]. Casati, F., Shan, M., "Dynamic and adaptive composition of e-services", Information Systems 26 (3), 143-162, 2001.

[3]. Cardoso J., and Sheth, A, " Semantic e-Workflow Composition", in the Journal of Intelligent Information Systems, 2002.

[4]. Cardoso, J., Sheth, A., and Miller J, "workflow Quality of Service", in Enterprise Inter- and Intra-Organizational Integration - Building International Consensus, Kosanke et al.(Eds), Valencia, Spain, Kluwer Academic Publishers, p.303-312, 2002.

[5]. Daniel A. Menasce, Virgilio A. F. Almeida, "capacity planning for Web Services, Metrics, Models and Methods, Prentice Hall, 2002.

[6]. Dmytro Dyachuk, Ralph Deters, "Improving Performance of Composite Web Services", IEEE International Conference on Service-Oriented Computing and Applications(SOCA'07), IEEE. 2007.

[7]. F. Casati, S. Ilnicki, and L. Jin. "Adaptive and dynamic service composition in eFlow." In Proc. 12th InternationalConference on Advanced Information Systems Engineering(CAiSE 2000), Stockholm, Sweden, June 2000, pp.13-31.

[8]. Greiner, U., Rahm, E., "Quality-oriented handling of exceptions in web-service-based cooperative processes", In Proceedings of EAIWorkshop 2004 - Enterprise Application Integration. GITO-Verlag, pp. 11-18, 2004.

[9]. J. H. Son, and M. H. Kim, "Improving the performance of time-constrained workflow processing", Journal of Systems and Software, Vol. 58(3), pp. 211 - 219, 2001.

[10].K. Kim, and C. A. Ellis, "Workflow performance and scalability analysis using the layered queuing modeling methodology", Proceedings of the International ACM SIGGroup Conference on Supporting Group Work, pp. $135-143,2001$

[11].Koo Lee Chun, Liew Pui Fong, and Norliza Katuk,"COMPOSITE WEB SERVICES TO SUPPORT TRAVEL INFORMATION SEARCHING", Proceedings of the 4th International Conference on Computing and Informatics, pp. 475-481, ICOCI 2013.
[12].K. Kim, and D. Han, "Performance and scalability analysis of client-server workflow architecture", Proceedings of the International Conference on Parallel and Distributed Systems, pp. 179 - 186, 2001.

[13].Kalai E, Zemel E, Generalized network problem yielding totally balanced games, Operations Research 30, 9981008, 1982

[14].Miller, J., Cardoso, J., and Silver, G., "Using Simulation to Facilitate Effective Workflow Adaptation," in Proceedings of 35th Annual Simulation Symposium, San Diego, CA, pp.177-181,2002.

[15].Narayanam, R., Narahari, Y. Shapley Value-Based Approach to Discover Influential Nodes in Social Networks, IEEE Transaction on Automation Science and Engineering, IEEE TASE, 2010.

[16].Pedro M. Reyes, "Logistics networks A game theory application for solving the transshipment problem", Applied Mathematics and Computation 168, 1419-1431, Elsevier, 2005.

[17].Shapley, L.S, A Value for n-Person Games", In H.W.Kuhn \& A.W.Tucker(eds), Annals of Mathematics Studies, 28, pp.307-317,1953.

[18].S. Yamaguchi, G. Qi-Wei, and M. Tanaka,"Performance evaluation on change time of dynamic workflow changes", IEICE Transactions on Fundamentals of Electronics, Communications, and Computer Sciences, pp. $2177-2187,2000$

[19].S. Haddad, L. Mokdad and S. Youcef, "Response Time Analysis for Composite Web Services", CSNDSPO8 proceedings, IEEE, 2008.

[20].S.Jagannatha, T. V Suresh Kumar, D.E. Geetha, and K. Rajanikanth, "Assessment of Workload Using Shapely Value in Distributed Database", Proceedings of International Conference on Advances in Computing, Advances in Intelligent Systems and Computing Volume 174, Springer, pp 31-40, 2012.

[21].T. Jaeger, and A. Prakash, "Management and utilization of knowledge for the automatic improvement of workflow performance", Proceedings of the Conference on Organizational Computing Systems, pp. $32-43$, 1995.

[22].Thomas Phan, Wen-Syan L, "Heuristics-Based Scheduling of Composite Web Service Workloads", MW4SOC '06, ACM, 2006.

[23].X. Fu, T. Bultan, and J. Su, "Formal Verification of EServices and Workflows", Lecture Notes In Computer Science; Vol. 2512, 188 - 202, 2002.

[24].Yi Chao-hui, Using Modified Shapley Value to Determine Revenue Allocation within Supply Chain, In International Conference on Information Management, Innovation Management and Industrial Engineering (2009), doi:10.1109/ICIII.2009.26, IEEE, 2009.

[25].Z. Tan, C. Lin, H. Yin, Y. Hong, and G. Zhu, "Approximate Performance Analysis of Web Services Flow Using Stochastic Petri Net", Lecture Notes in Computer Science, Vol.3251, pp. 193 - 200, 2004. 